\title{
Reading Vocabulary in Children With and Without Hearing Loss: The Roles of Task and Word Type
}

\author{
Karien M. Coppens, ${ }^{a}$ Agnes Tellings, ${ }^{a}$ Ludo Verhoeven, ${ }^{a}$ and Robert Schreuder ${ }^{b}$
}

\begin{abstract}
Purpose: To address the problem of low reading comprehension scores among children with hearing impairment, it is necessary to have a better understanding of their reading vocabulary. In this study, the authors investigated whether task and word type differentiate the reading vocabulary knowledge of children with and without severe hearing loss.

Method: Seventy-two children with hearing loss and 72 children with normal hearing performed a lexical and a use decision task. Both tasks contained the same 180 words divided over 7 clusters, each cluster containing words with a similar pattern of scores on 8 word properties (word class, frequency, morphological family size, length, age of acquisition, mode of acquisition, imageability, and familiarity).
\end{abstract}

\begin{abstract}
Results: Whereas the children with normal hearing scored better on the 2 tasks than the children with hearing loss, the size of the difference varied depending on the type of task and word.

Conclusions: Performance differences between the 2 groups increased as words and tasks became more complex. Despite delays, children with hearing loss showed a similar pattern of vocabulary acquisition as their peers with normal hearing. For the most precise assessment of reading vocabulary possible, a range of tasks and word types should be used.
\end{abstract}

Key Words: hearing loss, reading vocabulary, word type, task type
Without grammar, very little is conveyed; without vocabulary, nothing can be conveyed.

$$
\text { —Wilkens, } 1972 \text { (p. 111), as cited in Ludwig, } 1984
$$

$\mathrm{S}$ everal studies have highlighted differences in both the size and depth of reading vocabulary knowledge between children with normal hearing and children with hearing loss ${ }^{1}$ (Kelly, 1996; Marschark, Lang, \& Albertini, 2002; Paul, 1996, 2003). Children with hearing loss not only know fewer words but also know these words less well than children with normal hearing. Due to these limitations in vocabulary knowledge, many children with hearing loss have severe reading comprehension problems (LaSasso \& Davey, 1987; Luetke-Stahlman \& Nielsen, 2003; Paul, 2003; Wauters, van Bon, Tellings, \& van Leeuwe, 2006). To address the major problem of low reading

${ }^{1}$ For the purposes of this article, hearing loss is defined as a severe to profound bilateral hearing loss.

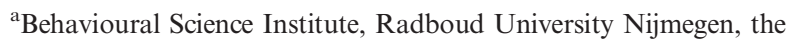
Netherlands

${ }^{\mathrm{b}}$ Donders Institute for Brain, Cognition and Behaviour, Centre for Cognition, Radboud University Nijmegen, the Netherlands

Correspondence to Karien M. Coppens: karien.coppens@gmail.com

Editor and Associate Editor: Janna Oetting

Received June 1, 2011

Revision received October 10, 2011

Accepted August 8, 2012

DOI: 10.1044/1092-4388(2012/11-0138)
}

comprehension scores by children with hearing impairment, it is necessary to have a better understanding of their reading vocabulary knowledge and development because vocabulary is a major predictor of reading comprehension. Furthermore, in-depth knowledge of their reading vocabulary knowledge and development is an essential condition for directing it. In the present study, we therefore investigated two important aspects of the already low vocabulary knowledge of children with hearing loss, namely the types of words children know and the types of word knowledge they have of these words. More specifically, we investigated whether task type and word type differentiate the reading vocabulary knowledge of children with and without severe hearing loss.

We first elaborate upon the acquisition of reading vocabulary in both children with and without hearing loss. Thereafter, we discuss in more detail how task type and word type may specify the differences in reading vocabulary knowledge between children with and without hearing loss.

\section{Reading Vocabulary Development and Hearing Status}

There is a close relationship between the acquisition of language and the development of literacy (see S. W. Beck \& Nabors Oláh, 2001). Children with normal hearing initially build their (spoken) vocabularies primarily on the basis of hearing or overhearing speech in a wide variety of contexts that allow them to discover the referential meanings of words (Bloom \& German, 2000). The later reading vocabularies are 
built on their spoken language vocabularies (Hanson, Shankweiler, \& Fischer, 1983; Hermans, Knoors, Ormel, \& Verhoeven, 2008; Leybaert, 1993). Vocabulary refers to the knowledge of words and word meanings (Miller, 1999), and reading vocabulary refers specifically to the knowledge of written words.

The spoken vocabularies of children with normal hearing have been shown to be strongly related to both the quality and quantity of language that they hear from the people around them (Hart, 1991; Huttenlocher, Haight, Bryk, Seltzer, \& Lyons, 1991; Weizman \& Snow, 2001). The first words that children produce, the variation observed in their vocabulary sizes, and the rates of their vocabulary growth are tightly linked to the characteristics of their parents' speech (Hart, 1991; Huttenlocher et al., 1991). Up to kindergarten and even second grade, nearly one third of the variation in the vocabulary performance of children can be accounted for by the variation observed in the speech of their mothers (Weizman \& Snow, 2001). Children who begin schooling with strong spoken language abilities, moreover, have a head start for the development of literacy skills (Mayer, 2007). And a robust body of evidence shows a broad range of oral language skills to be the foundation for early and long-term literacy success in the case of children with normal hearing (for an in-depth discussion, see Dickinson, McCabe, \& Essex, 2006).

For children with hearing loss compared to children with normal hearing, their initial language input-whether spoken or signed - is reduced (Mayberry, 2002; Spencer \& Lederberg, 1997). The critical association between spoken language skills and early literacy development can thus be disrupted for children with hearing loss in at least two ways. First, exposure to early spoken word-learning opportunities is limited by profound hearing loss (Fagan \& Pisoni, 2010; Auer, Bernstein, \& Tucker, 2000). Thus, children with severe hearing loss have obviously not acquired a spoken language system in the way that children with normal hearing have, which can negatively affect their development of the skills needed to become literate (Mayer, 2007). Second, children with severe hearing impairment whose first language is not spoken but rather sign language may be faced with the acquisition of the skills needed to become literate in a language they are not familiar with (i.e., a written language as opposed to sign language; Mayer, 2007). In addition, children with hearing loss usually do not have full mastery of sign language because $95 \%$ of such children have parents without hearing loss; therefore, usually they do not have full access to sign language from an early age (Ormel, 2008).

\section{The Role of Task Type in Reading Vocabulary Development}

To study children's vocabulary development or word knowledge, we have to consider what it means to "know" a word (I. L. Beck \& McKeown, 1991). An extensive and widely used approach is the model of Nation (1990, p. 31) in which word knowledge is represented in terms of its different components: form, position, function, and meaning. The model also differentiates between receptive and productive word knowledge. Another widely used conceptualization of word knowledge is the very rough but useful continuum proposed by Dale (1965), who distinguished four stages ranging from stage 1, no knowledge, to stages 2 and 3 , incomplete or partial knowledge, to stage 4 , full knowledge. Thus, instead of a dichotomous phenomenon (i.e., you either know a word or you do not), word knowledge is construed as a continuous concept.

Given that word knowledge consists of many different components, different types of tasks are called for to assess vocabulary knowledge (Read, 2000). Some tasks focus mainly on the number of words that are known. The respondent may thus be presented with multiple-choice items concerned with the meanings of words, as in the Peabody Picture Vocabulary Test-III (Dunn \& Dunn, 1997), or with a lexical decision task in which the respondent has to decide whether a string of letters is a word or not, as in the go/no go test (Huibregtse, Admiraal, \& Meara, 2002). Other tasks assess how much the respondent knows about a word and thus test either one or various aspects of the respondent's word knowledge, as in the Vocabulary Levels Test (Nation, 1990) or the Word Comprehension subtests of the Woodcock Reading Mastery Tests - Revised, which examine antonyms, synonyms, and analogies (Woodcock, 1987).

The results of previous studies suggest that the nature of the differences in the vocabulary knowledge of children with hearing loss versus children with normal hearing may depend upon - among other things - the type of task administered (Fischler, 1985; Luckner \& Cooke, 2010; Marschark, Convertino, McEvoy, \& Masteller, 2004; Moeller, 2000; Paul \& Gustafson, 1991). Some studies find the size of the difference to depend upon the type of task (e.g., the difference in scores between children with and without hearing loss is larger on Task A than on Task B). For example, when Paul and Gustafson (1991) asked students with and without hearing loss to select either one or two meanings for multimeaning words, students with normal hearing outperformed those with hearing loss, and the selection of two meanings was more difficult than the selection of a single meaning in both groups. More important, the difference between the groups was larger when the students were asked to select two meanings as opposed to one. When Moeller (2000) compared the expressive versus receptive vocabularies of children with hearing loss versus children with normal hearing, the expressive vocabularies of the children with hearing loss lagged behind the expressive vocabularies of the children with normal hearing less than the receptive vocabularies of the children with hearing loss lagged behind the receptive vocabularies of the children with normal hearing.

Other studies have found differences in the types of tasks that are most difficult for children with hearing loss versus children with normal hearing (e.g., whereas Task A is more difficult than Task B for one group, the opposite is found to be the case for the other group: Task B is more difficult than Task A). Marschark et al. (2004) used a word association task involving superordinate-subordinate relations (e.g., fruit to 
the word apple, and apple to the word fruit) and an analogysolving task involving such relations (e.g., apple : fruit $\because:$ dog : ) to determine how students with hearing impairment classify and categorize concepts relative to students with normal hearing. On average, the students with hearing loss were less successful on the analogies than their peers with normal hearing but had surprisingly fewer problems with the analogies requiring the provision of a subordinate term than with the analogies requiring the provision of a superordinate term; the opposite was found to be the case for the children with normal hearing (Marschark et al., 2004). In other research, Fischler (1985) found a task in which words are presented in isolation or in context to have different effects for students with hearing loss versus students with no hearing loss: He examined the effects of supportive, incongruent, unlikely but acceptable, and absent sentence contexts on response times in a lexical decision task. In contrast to students with normal hearing, who tended to benefit from the available sentence context when it is supportive, students with hearing loss always responded faster on the no-context trials than on the sentence-context trials.

In the present study, we therefore used two tasks to assess the development of children's reading vocabulary: a lexical decision task and a use decision task. The lexical decision task measured the child's ability to recognize a string of letters as a real word or a pseudoword (Stage 1 of Dale's [1965] continuum). This is obviously a necessary condition for understanding the meaning of a word. The socalled use decision task measured the child's deeper ability to recognize the correct/incorrect usage of a word and thus represents an extension of Stage 3 of Dale's continuum. Using these two types of tasks, we were able to measure not only two different components of reading vocabulary but also whether the differences between children with and without hearing loss varied per task. In a related study by Coppens, Tellings, Verhoeven, and Schreuder (2011), children with hearing loss were recently found not only to know fewer words than children with no such hearing loss but also to know the words they know less well. This lack of deeper vocabulary knowledge remained, even when the children with and without hearing loss were matched with regard to the words they recognized in a lexical decision task.

In the present study, we investigated the differences in vocabulary knowledge between children with and without hearing loss in more detail by looking not only at the type of knowledge (minimal or deeper vocabulary knowledge) but also at the type of word or possibly an interaction between these, since there are indications that both of these variables might specify vocabulary knowledge further. Knowledge of the influence of task type and word type will help to develop more fine-tuned vocabulary measurement tasks and intervention methods.

\section{The Role of Word Type in Reading Vocabulary Development}

Vocabulary should be explored not only by using a broad range of tasks but also by focusing on different word properties. In the literature, researchers have demonstrated that various word properties play a role in vocabulary development and word processing. There seems to be a consensus on the effects of word properties such as frequency, age of acquisition (AoA), and imageability (IMA) on the acquisition and processing of a word (for an overview, see Balota, Yap, \& Cortese, 2006). However, these effects have been studied in mostly hearing adults and children (Balota, 1994; Schreuder \& Baayen, 1997); there is relatively little research on the effects of word properties in adults and children with hearing loss.

In the limited research on the effects of word properties on the vocabulary development and word processing of children and adults with hearing loss, Cuetos, Monsalve, Pinto, and Rodriguez-Ferreiro (2004) investigated the effects of familiarity (FAM), AoA, word frequency, and word length on the lexical production of adolescents and adults with hearing loss. As they did in studies with hearing participants, both AoA and word frequency showed statistically significant effects on the performance of the respondents with hearing loss, and thus no differential effects for the two groups of respondents were found. The effects of mode of acquisition (MoA) have been investigated by Wauters, Tellings, van Bon, and Mak (2008). MoA refers to the type of information that is used to acquire the meaning of a word. For instance, the word ball is usually learned through perception of the referent of the word; the word grammar is usually learned through linguistic information such as a verbal or written explanation; other words may be learned through a combination of both modes. Wauters et al. found MoA to similarly predict reading times in children with and without hearing loss: Both groups scored lower on the comprehension of so-called linguistic items than on the comprehension of so-called perceptual items.

Some word properties are highly intercorrelated, which means that the predictive power of a single property may be limited. Linear modeling techniques can be used to incorporate higher order interactions, but the interpretation of a model with interactions between more than three predictors can quickly become unwieldy. Yet, not all word properties are highly correlated (e.g., length and IMA, and word class and frequency). Moreover, some properties might only correlate under certain conditions. For instance, chips, circle, and choice are all short nouns; however, chips is highly imageable but not used frequently in written discourse, circle is both highly imageable and frequently used in written discourse, and choice is not very imageable yet frequently used in written discourse. Thus, word properties might correlate in various ways, and finding out how particular combinations of word properties predict performance on word tasks would necessitate the inclusion of many interaction terms.

Recently, Tellings, Coppens, Gelissen, and Schreuder (2013) collected information on eight word properties that have been shown in several studies to influence the mental processing of words (for an overview, see Bayyen, 2005; Balota \& Chumbley, 1984; Balota et al., 2006). For 703 words, Tellings et al. collected information on the word class, 
Table 1. Cluster probabilities for word class and cluster averages for other variables.

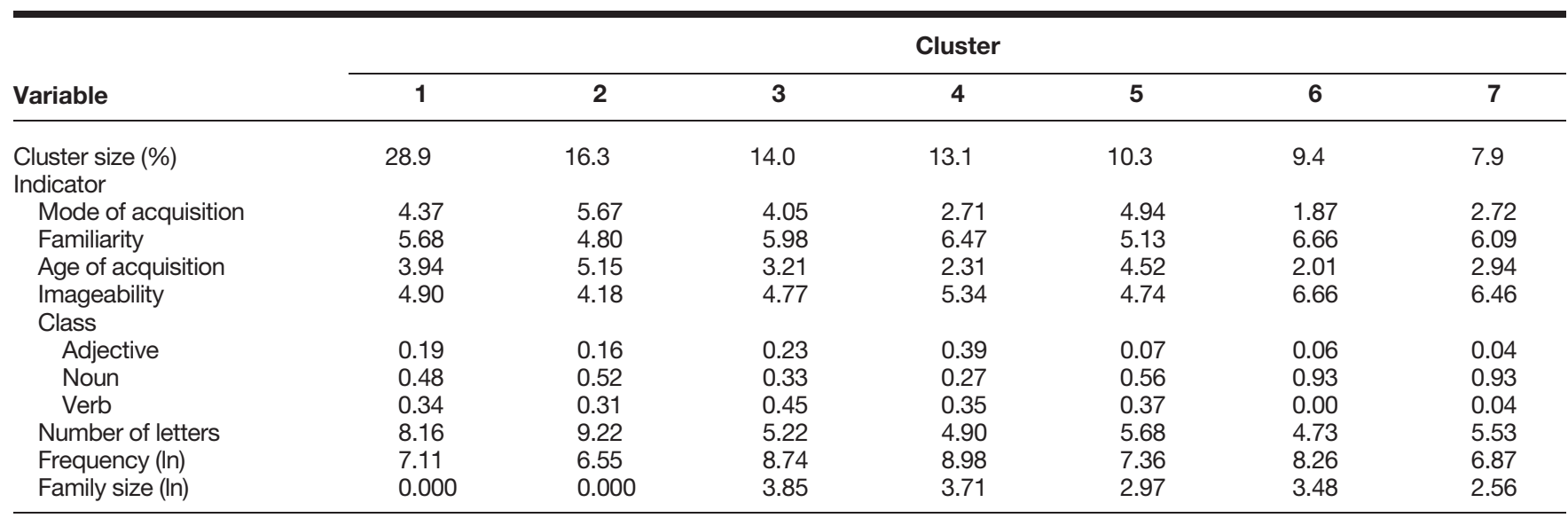

Note. In = natural logarithm. From “Clusters of Word Properties as Predictors of Elementary School Children's Performance on Two Word Tasks," by A. Tellings, K. Coppens, J. Gelissen, and R. Schreuder, 2013. Applied Psycholinguistics, 34, 461-481. Copyright 2013 by Cambridge University Press. Reprinted with permission.

length, frequency, morphological family size, ${ }^{1}$ AoA, MoA, FAM, and IMA. An exploratory latent class cluster analysis was then conducted (Vermunt \& Magidson, 2000). The strength of such an analysis is that it identifies latent clusters (i.e., subgroups of words) within the sample with particular configurations of properties as opposed to subgroups with a common underlying dimension or dimensions, which is the strength of factor analysis. Seven latent clusters of words or, stated differently, types of words could be identified within the sample - each with a unique configuration of word properties (for further details on data collection and analysis, see Tellings et al., 2013). For every word, the probability of belonging to each of the seven clusters was computed during the cluster analysis, and each word was then assigned to that cluster for which it had the highest modal probability of being assigned. The clusters were then numbered according to size: the percentage of the total number of words contained by that cluster. In Table 1, the size is given for each cluster, the probability of the words in this cluster to belong to a certain word class (with the figures for the three word classes adding up to one), and the cluster averages for the other variables. AoA, MoA, FAM, and IMA were scored along 7-point scales. A higher score (with a maximum of 7) means a later age of acquisition and acquisition more via language, respectively; a lower score means acquisition more via experience, more FAM, and higher IMA, respectively. Length, frequency, and family size were count variables; the latter two were scored as log frequencies.

Scores on these three word properties can, in principle, be higher than 7. In Table 2, a brief description and examples of words with a 1.0 probability of belonging to a particular cluster are presented. For the sake of convenience, we have also labeled the different clusters, mainly in terms of their

\footnotetext{
${ }^{1}$ Morphological family size is the number of complex words in which a base word occurs as stem (e.g., work-homework).
}

linguistic form and register. Note that these labels are global indications of the majority of the words occurring in a given cluster. By complex words (Clusters 1 and 2), we mean compounds such as "goldfish" and "bookcase" and derivationally complex words such as "fisher" and "childhood." By simple words (Cluster 5), we mean monomorphemic or inflected words. Common (Clusters 4 and 6), ordinary (Clusters 1 and 3), and specific (Clusters 2 and 5) can be seen to constitute a register-continuum. Specific refers to words that are typical of the corpus they are taken from (i.e., assessment tests for the end of elementary school: many words refer to arithmetic, to geography, to test taking; see the examples in Table 2), ordinary refers to more general concepts, and common to everyday concepts. Generic refers to the degree to which words are not bound to a specific semantic domain (e.g., "man" is more generic than "elephant"; see Magnini, Strapparava, Pezzulo, \& Gliozzo, 2002). Tellings et al. (2013) also showed Cluster 7 to differ from the other clusters in having consistently low factor loadings.

Tellings et al. (2013) subsequently found the seven clusters they identified to explain the performance of children with normal hearing on a lexical and a use decision task. Therefore, we expect these seven clusters to help us decide whether the differences in the vocabulary knowledge of children with hearing loss versus no hearing loss vary depending on word type.

\section{The Present Study}

In the present study, we wanted to investigate the reading vocabulary of children with and without hearing loss throughout elementary school, taking into account type of words and type of knowledge. Therefore, we administered two reading vocabulary tasks with target words from the seven clusters (i.e., word types) from the study by Tellings et al. (2013) to a group of children with normal hearing and a 
Table 2. Description for each of the seven clusters.

\begin{tabular}{|c|c|c|}
\hline Cluster & Description & Examples \\
\hline Cluster 1: Complex ordinary words & $\begin{array}{l}\text { Derivationally complex words and compounds, learned } \\
\text { relatively early, fairly easy to imagine }\end{array}$ & $\begin{array}{l}\text { familielid [family member], nachtmerrie } \\
\text { [nightmare], terugkrijgen [to get back], }\end{array}$ \\
\hline Cluster 3: Generic ordinary words & $\begin{array}{l}\text { Largest difference between frequency and imageability, } \\
\text { often multiple-meaning words }\end{array}$ & $\begin{array}{l}\text { deel [part], druk [pressure], nemen [to } \\
\text { take] }\end{array}$ \\
\hline Cluster 5: Simple specific words & $\begin{array}{l}\text { Monomorphemic and inflected words, learned relatively } \\
\text { late, hard to imagine, specific words }\end{array}$ & $\begin{array}{l}\text { gram [gram], massa [masses], museum } \\
\text { [museum] }\end{array}$ \\
\hline Cluster 6: Common basic words & $\begin{array}{l}\text { Mostly very basic, short nouns that are both frequent and } \\
\text { highly imageable }\end{array}$ & fiets [bike], hond [dog], schoen [shoe] \\
\hline Cluster 7: Other words & Quite imageable but less familiar words & $\begin{array}{l}\text { toeter [hooter], kous [stocking], tram } \\
\text { [streetcar] }\end{array}$ \\
\hline
\end{tabular}

group of children with hearing loss in Grades 3-6. The words in the two tasks come from an end of elementary school test, thus, words children should know at the end of Grade 6.

We did not include the youngest children because we assumed that they might have insufficient decoding skills to perform the tasks. This approach enabled us to examine the differences in the vocabulary knowledge of the children and tease out how task demands and word type might influence the assessment of the children's reading vocabulary knowledge.

\section{Method}

\section{Participants}

This study is part of a larger longitudinal project in which 130 children with severe hearing loss and 468 children with normal hearing participated. Participants in the present study were 144 children in grades 3 through 6 (age range of 8-13 years) from 33 elementary schools throughout the Netherlands (132 children also participated in the study of Coppens et al., 2011; 37 children also participated in the study of Tellings et al., 2013). The schools and institutions approved each child's participation prior to the conduct of the research. Parental consent was also secured for all children.

The participant group consisted of two groups: 72 children with normal hearing and 72 children with hearing loss. Each child with hearing loss was matched to a child with normal hearing of the same sex, approximately the same age, and equivalent word decoding skills. We matched the children in order to ensure that observed differences in vocabulary knowledge were not due to poorer word decoding skills. Decoding skills were measured using the Pencil-and-Paper Lexical-Decision Task of van Bon (2007). This task measures word decoding without requiring participants to read out loud, which tends to be a problem for most children with severe hearing loss. We were able to match the children because our longitudinal group consisted of many children with and without hearing loss, also because the word decoding skills did not differ much for the children with hearing loss versus normal hearing - which is similar to what has been found in previous studies (e.g., Fischler, 1985; Wauters, van Bon, \& Tellings, 2006).

Each group was composed of 41 boys and 31 girls. The mean age of the children with normal hearing at test administration was $10 ; 11$ (years;months; $S D=1 ; 2$ ). The mean age of the children with hearing loss was $11 ; 0(S D=$ $1 ; 2)$. The children with hearing loss all had a loss of at least $80 \mathrm{~dB}$ in the better unaided ear. Of the 72 children with hearing loss, 46 children used spoken Dutch at home; 20 of the 46 combined spoken Dutch with sign-supported Dutch. Four children used another spoken language at home, six children only sign-supported Dutch, and one child Sign Language of the Netherlands. The remaining 15 children used combinations of Sign Language of the Netherlands, sign-supported Dutch, and a spoken language at home. Detailed information on the children with hearing loss can be found in the Appendix.

\section{Target Words}

The target words were taken from the Cito Eindtoets Basisonderwijs [End of Elementary School Test] for the years 2004, 2005, and 2006 (for information about this test, see van Boxtel \& Hemker, 2009). This standardized test is administered in sixth grade in about $90 \%$ of all Dutch elementary schools to determine which high school is suitable for the child. The test is a test of general knowledge and thus includes sets of language tasks, mathematics tasks, and tasks that measure study skills; the wording of these tasks can thus be seen to represent an implicit norm for words that children should have acquired during elementary school. For a detailed description of the construction of the list of 703 words, see Coppens et al. (2011). The list of 703 words contained nouns $(n=367)$, verbs $(n=209)$, and adjectives $(n=127)$. From the 703 words, 180 target words were selected for use in the present study.

\section{Lexical Decision Task}

For the lexical decision task, we created a phonologically and orthographically legal Dutch pseudoword for each 
of the 180 target words. To ensure that the variation in the structure of the pseudowords, possible word class, and length of the pseudowords approximately mirrored that of the 180 target words, we first selected words that were similar to the target words with regard to these factors from the CELEX database, a large electronic database that provides detailed Dutch lexical data (Baayen, Piepenbrock, \& Gulikers, 1995). We then altered this word by one or two letters to create the pseudoword while still adhering to the phonotactic and orthographic constraints of Dutch. The 180 words and 180 pseudowords were next randomized and divided into three lists with 120 items each (60 target words and 60 pseudowords).

\section{Use Decision Task}

The use decision task was aimed at measuring a deeper form of understanding for the target words by determining whether the child recognized the incorrect/correct usage of the word. For this, we created four short sentences to accompany each target word, such that the target word was used semantically, syntactically, and morphologically correct in only one of the four sentences (e.g., The train goes). The incorrect alternatives were syntactically and morphologically correct but semantically incorrect (e.g., The train sings, The train sleeps, The train walks). We incorporated the 180 target words with their accompanying four sentences into three PowerPoint presentations with 60 target words for presentation in a session.

\section{Procedure}

We divided testing into three sessions to minimize the workload per session. Each session consisted of a lexical decision task and a use decision task. The participants completed the use decision task after completion of the lexical decision task. The 60 words in the use decision task were the same as the 60 target words used in the preceding lexical decision task but were presented in a different order. To control for order effects, there were four versions of both the lexical and the use decision task, and these were randomly distributed across the classes. One classroom (or group) of children was tested at a time by the first author.

The children were instructed in the modality they preferred (either Sign Language of the Netherlands or spoken Dutch). For the lexical decision task, we asked the children to read the letter strings on the list column by column and to cross out the pseudowords. Lexical decision tasks can be performed both in written form and orally, with and without time pressure, depending on the objective of task administration. Previous studies support the idea that although the task technically only requires pattern recognition, word knowledge is activated during the lexical decision task - both in adults (Balota \& Chumbley, 1984) and children (Marcolini, Burani, \& Colombo, 2009). Our objective was to find out if the children identified the written letter string as an existing Dutch word or not for each and every item. We therefore administered the lexical decision task without time pressure. In general, administration of each of the three lexical decision tasks took about $10 \mathrm{~min}$, including instruction.

After having performed the lexical decision task, the children performed the use decision task. The target word and sentences were projected onto a screen with a beamer. The children were instructed to read the target word together with the four sentences, choose the sentence in which the target word was used best, and mark this on their answering sheets. Each of the use decision task sessions took approximately $40 \mathrm{~min}$, including instruction.

\section{Results}

The cluster analyses conducted by Tellings et al. (2013) were completed after the conduct of the present study and showed eight of the words in our sample to have a very small probability of belonging to a distinct cluster; these words were therefore omitted from the analyses for the present study. The distribution of the remaining 172 words across the seven clusters was as follows: 58 words in Cluster $1(27.8 \%)$, 44 words in Cluster $2(21.1 \%), 20$ words in Cluster $3(9.6 \%)$, 19 words in Cluster 4 (9.1\%), 10 words in Cluster 5 (4.8\%), 13 words in Cluster $6(6.2 \%)$, and 16 words in Cluster 7 (7.7\%). A brief description of the clusters can be found in Table 2 .

For each child, we calculated the proportion of the words scored correct for each of the seven clusters on the lexical decision task and use decision task separately (see Table 3). We performed one-way analyses of variance (ANOVAs) with Bonferroni adjustments to see whether the $M$ s differed significantly. Scores of the children with normal hearing were significantly higher than the scores of the children with hearing loss for all clusters $(p<.01)$ except for Clusters 4, 6, and 7 in the lexical decision task ( $p=.19, p=$ .89 , and $p=.36$, respectively). The results depicted in Figure 1 clearly show the dispersion of the words scored correctly across the different clusters on the two tasks to differ for the two groups. Differences in scores between children with and without hearing loss seem to be larger on the use decision task than on the lexical decision task, and for Clusters 1, 2, and 5 in comparison with Clusters 4 and 6 .

We next conducted a repeated measurement analysis with Hearing Status as a between-subjects factor, and both Cluster (or word type) and Task Type as within-subjects factors. Cluster had seven levels (Clusters 1 to 7) and Task Type had two levels (lexical decision task or use decision task). Mauchly's test indicated that the assumption of sphericity was violated for the main effect of Cluster, $\chi^{2}(20$, $N=144)=538.55, p<.001$, and for the Cluster $\times$ Task Type interaction, $\chi^{2}(20, N=144)=293.26, p<.001$. Therefore, we corrected the degrees of freedom using Greenhouse-Geisser estimates of sphericity $(\varepsilon=.38$ for the main effect of Cluster and .53 for the Cluster $\times$ Task Type interaction).

\section{Main Effects and Interactions}

As observed in previous studies, we found a main effect of Hearing Status and an interaction between Hearing Status and Task Type (see Table 4). The main effect of Hearing Status indicates that children with hearing loss obtained 
Table 3. Proportion of words scored correct for each of the seven word clusters in the two tasks.

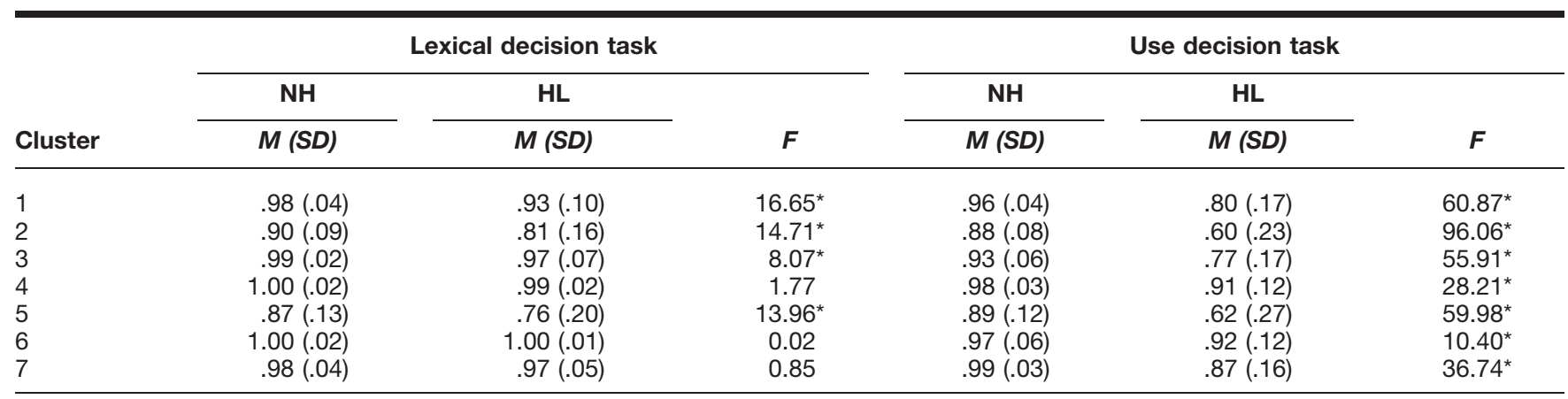

Note. $\mathrm{NH}=$ children with normal hearing; $\mathrm{HL}=$ children with hearing loss.

${ }^{*} p<.01$ (two-tailed).

Figure 1. Performance of children with normal hearing and children with hearing loss on seven word clusters in the lexical decision task (LDT) and use decision task (UDT). Error bars represent proportion of words responded to correctly and the range of the children's scores. The bottoms and tops of the boxes indicate the 25th and 75th percentiles; the line near the middle of the box is the 50th percentile (i.e., median). The ends of the vertical lines indicate the lowest and highest data points still within the 1.5 interquartile range for the lower and upper quartiles, respectively.
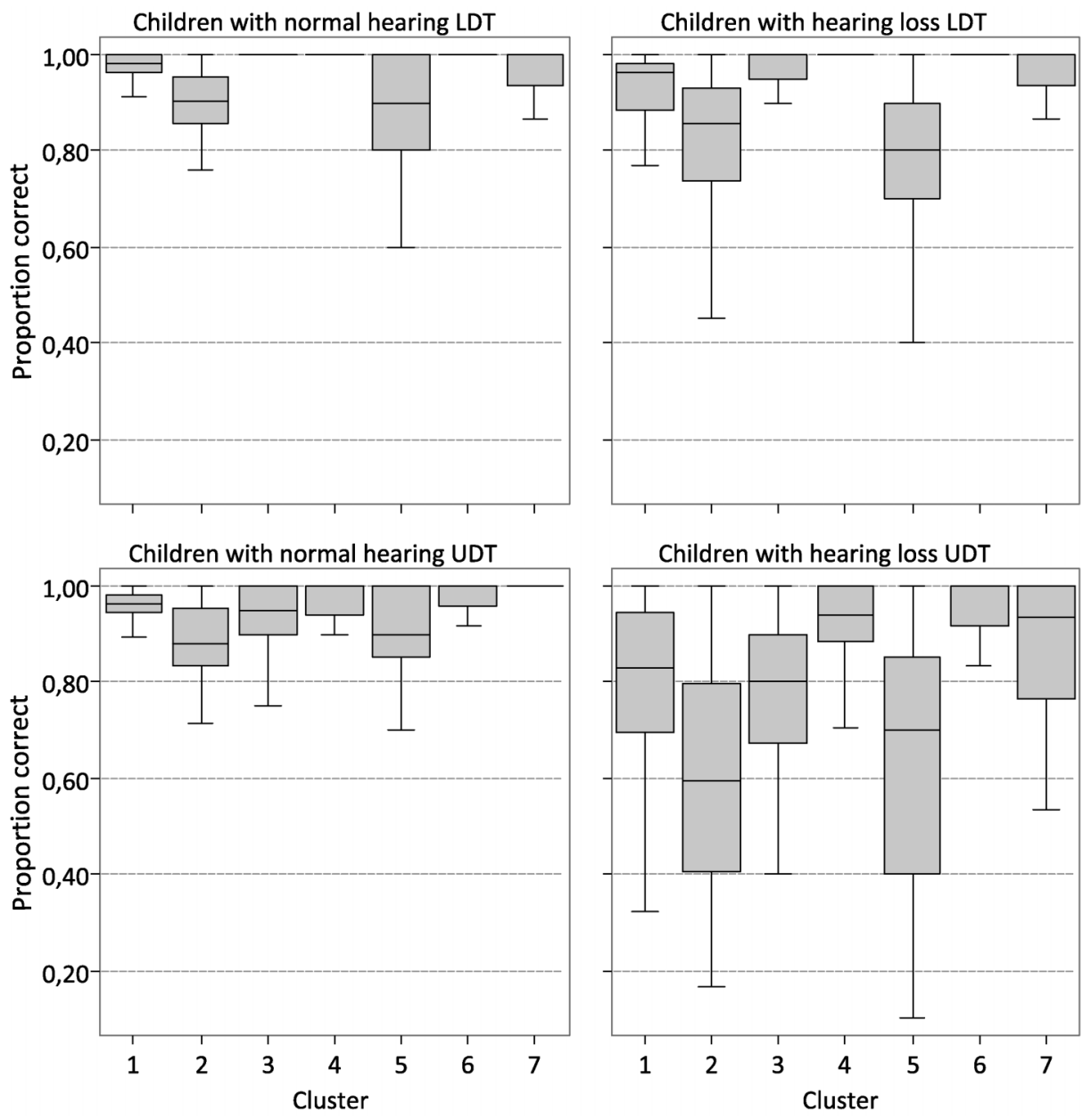
Table 4. Effects of repeated measurement analysis.

\begin{tabular}{lcc}
\hline Effect & $\boldsymbol{F ( d f )}$ & Wilks's $\mathbf{~}$ \\
\hline Hearing Status & $F(1,142)=58.58$ & \\
Task Type & $F(1,142)=107.0$ & .570 \\
Cluster & $F(6,321.9)=199.28$ & .275 \\
Hearing Status $\times$ Task Type & $F(1,142)=67.22$ & .679 \\
Hearing Status $\times$ Cluster & $F(6,321.9)=33.80$ & .692 \\
Cluster $\times$ Task Type & $F(6,452.2)=17.47$ & .490 \\
Hearing Status $\times$ Task Type $\times$ & $F(6,452.2)=9.91$ & .733 \\
$\quad$ Cluster & & \\
\hline
\end{tabular}

Note. All effects are reported as significant at $p<.001$.

lower scores on the reading vocabulary tasks than their peers with normal hearing. The interaction between Hearing Status and Task Type indicates that the difference in performance for the children with and without hearing loss nevertheless depended on task type: The difference between the children with hearing loss and the children with normal hearing was greater in the use decision task than in the lexical decision task. This difference can be explained by the ease of the lexical decision task, which requires relatively shallow knowledge of a word (i.e., only recognition of correct orthography to respond), whereas the use decision task requires more in-depth knowledge of the target words along with knowledge of the words and grammatical structures used in the accompanying sentences.

Importantly, results also revealed a significant threeway interaction between Hearing Status, Task Type, and Cluster, which means that the children with and without hearing loss responded differently to the word clusters and that the way in which they responded to the word clusters was not the same for the two tasks. The children were differentially sensitive to the types of words presented.

\section{Similarities and Differences Based on Hearing Status}

To gain greater insight into the detected differences in the children's performance in response to the seven clusters of words in the two vocabulary tasks, we performed general linear model repeated-measures ANOVAs for the two groups separately, with Cluster (1 to 7) and Task Type (lexical decision task vs. use decision task) included as within-subject factors and Bonferroni adjustments for each measure/task. On the basis of the descriptive statistics and Bonferroni adjustments, we were able to order the clusters from those eliciting the lowest scores to those eliciting the highest scores in the different tasks for the two groups of children and thereby identify the significant differences between the children's scores in response to the clusters (i.e., word types), as shown in Table 5. We discuss the results per task below.

Lexical decision task. For the lexical decision task, similar results were found for the children with and without hearing loss when Cluster 7 was left out of consideration (see Table 5). Recall that Tellings et al. (2013) showed Cluster 7 to have consistently low factor (i.e., word) loadings and thus differ from the other clusters. Both children with and without hearing loss scored significantly lowest on the specific words from Clusters 2 and 5; significantly best on the common words from Clusters 4 and 6. Performance on the ordinary words from Clusters 1 and 3 was in between performance on the other clusters for both groups, although the children scored significantly better on the generic ordinary words from Cluster 3 than on the complex ordinary words from Cluster 1. The scores of the children with normal hearing on the words from Cluster 3 or the generic ordinary words also did not differ significantly from their scores on the common words in Clusters 4 and 6.

Use decision task. Just as in the lexical decision task, the order of the clusters in the use decision task was identical for the children with hearing loss and the children with normal hearing, with the exception of Cluster 7 and a change of position for Clusters 4 and 6: The children with hearing loss obtained the highest scores on the common basic words from Cluster 6 and the children with normal hearing on the common generic words from Cluster 4 . The mean score differences for Clusters 4 and 6 were not significant, however (see Table 3).

Inspection of the significant cluster differences shows both the children with and without hearing loss to again score lowest on the specific words from Clusters 2 and 5. The one exception to this pattern was as follows: The mean score on the simple specific words from Cluster 5 for the hearing children did not differ significantly from the mean score for these children on the generic ordinary words from Cluster 3. Both the children with and without hearing loss performed best on the words from Clusters 4, 6, and 7. However, the children with normal hearing did not score significantly different on the common basic words from Cluster 6 than on the complex ordinary words from Cluster 1.

\section{Discussion}

This study yielded three major findings with implications for understanding individual and group differences in the vocabulary knowledge of children with and without severe hearing loss. First, we found that the children with normal hearing produced better scores on the two vocabulary knowledge tasks that we used and on seven clusters of words (i.e., word types) than the children with hearing loss. The vocabulary knowledge of children with hearing loss is thus smaller and also less in-depth than the vocabulary knowledge of children with normal hearing. This difference is probably due to the fact that hearing loss limits exposure to words (Fagan \& Pisoni, 2010), and many children with hearing loss are relatively deprived of linguistic input (Mayberry, 2002; Spencer \& Lederberg, 1997). Therefore, many children with hearing loss not only encounter fewer words but also encounter each of these words less often than children with normal hearing. Research indicates that students with normal hearing need to encounter a word at least 12 times (McKeown, Beck, Omanson, \& Pople, 1985) or even up to 40 times (Reutzel \& Cooter, 2004) to know the 
Table 5. Order of clusters in two tasks and significant differences between clusters with Bonferroni adjustments for both groups.

\begin{tabular}{lll}
\hline Task & \multicolumn{1}{c}{ NH } & \multicolumn{1}{c}{ HL } \\
\hline Order in lexical decision task $^{2}$ & 5217346 & 5213746 \\
Significant differences $^{a}$ & $52<17346$ & $52<13746$ \\
& $1<346$ & $1<3746$ \\
& $7<46$ & $37<46$ \\
Order in use decision task $^{a}$ & 2531647 & 2531746 \\
Significant differences $^{a}$ & $2<31647$ & $25<31746$ \\
& $53<1647$ & $31<746$ \\
& $1<47$ & $7<6$ \\
\hline
\end{tabular}

$a_{1}=$ complex ordinary words, 2 = complex specific words, $3=$ generic ordinary words, $4=$ common generic words, $5=$ simple specific words, $6=$ common basic words, $7=$ other words.

words well enough to support reading comprehension (Luckner \& Cooke, 2010), depending on both the word to be acquired and the age, vocabulary skills, and reading proficiency of the student. The present results thus emphasize the importance of frequent encounters with a word in differing contexts in order to establish and deepen vocabulary knowledge. The knowledge framework surrounding a word is essential for comprehending discourse (Paul, 1996).

Second, we found that the differences in the vocabulary knowledge scores of the children with and without hearing loss vary depending on the type of task and word. Previous studies have reported quantitative differences per task (Kyle \& Harris, 2006; Marschark et al., 2004; McEvoy, Marschark, \& Nelson, 1999; Moeller, 2000; Paul \& Gustafson, 1991). And in keeping with these studies, we found the differences in the scores of the children with and without hearing loss to be larger on the use decision task than on the lexical decision task. Although the children's scores were similar on the common words from Clusters 4 and 6 in the lexical decision task (i.e., the easiest words in the easiest task), large differences were observed between the children with and without hearing loss on the specific words from Clusters 2 and 5 in both tasks (i.e., the most difficult words). Thus, the vocabulary differences between the children with normal hearing and the children with hearing loss increased as the words and tasks became more complex and the tasks required a deeper understanding of the semantic context for a word, as depicted in Figure 1. Even when children with hearing loss can recognize a pattern of letters as representing an existing word in a lexical decision task, it is not certain that they have sufficient lexical-semantic knowledge to recognize correct usage of the same word in a sentence (i.e., for communication).

A third major finding with implications for understanding individual and group differences in the vocabulary knowledge of children with and without severe hearing loss was the finding that although the children with hearing loss generally produced lower scores on the two vocabulary tasks that we used and for different word types than the children with normal hearing, the same types of tasks and words proved relatively "difficult" and "easy" for the two groups of children. For both the children with and without hearing loss, recognition of the correct usage of a word in a sentence was more difficult than identification of a string of letters as an existing (Dutch) word. Previous studies with participants with and without hearing loss have similarly found quantitative but not qualitative responses to depend on the type of task and vary with the type of task (Kyle \& Harris, 2006; McEvoy et al., 1999; Moeller, 2000; Paul \& Gustafson, 1991). When McEvoy et al. (1999) administered a semantic association task, they found relatively similar sets of responses for students with and without hearing loss despite variation in the response sets of the students in terms of coherence and access of the lexical concepts. In other research, quantitative but no qualitative differences were again found: When Kyle and Harris (2006) presented children with a number of tasks to assess their reading, spelling, productive vocabularies, speech reading, phonological awareness, short-term memories, and nonverbal intelligence, they found important quantitative differences between the performances of the children with and children without hearing loss on the different tasks; their performances were qualitatively similar with regard to sensitivity to spelling-sound regularities and congruency of word phonology and orthography when making phonological judgments. Marschark et al. (2004) mentioned some qualitative differences in the performance of students with versus without hearing loss when asked to provide exemplars and category names (fruit vs. banana) on a word association task and subordinate relations (snake : reptile :: banana :__ ) and superordinate relations (e.g., fruit : banana :: flower : in an analogies task, but they argue that these tasks require other cognitive skills in addition to vocabulary knowledge.

Although the scores of the children with and without hearing loss also differed across the seven clusters of words (i.e., types of words), our results show that the relative order of the cluster scores to be more or less similar for the two groups of children on both the lexical decision task and use decision task. Both the children with and without hearing loss scored best on common words and worst on specific words. Even though profound hearing loss limits exposure to words (Fagan \& Pisoni, 2010) and children with such hearing loss have a different pattern of word experience than children without profound hearing loss (Auer et al., 2000; Lederberg, Prezbindowski, \& Spencer, 2000), the children with hearing loss in our study showed patterns of vocabulary development and word processing that were remarkably similar to the patterns of vocabulary development and word processing found for their peers with normal hearing.

These findings confirm the qualitative similarity hypothesis of Paul (2001; Paul \& Lee, 2010). According to Paul, the development of language and literacy skills of children with hearing loss is delayed but otherwise qualitatively similar to that of children with normal hearing. Similarly, Cuetos et al. (2004) provides evidence that the organization of the lexical system in individuals with hearing loss is largely similar to the organization of the lexical system in individuals with normal hearing. And our findings appear to support both of these sets of findings. 


\section{Possible Limitations and Directions for Future Studies}

Our results show that different tasks and target words with different patterns of word properties differentially affect the performance differences between children with and without hearing loss. Our study has some possible limitations and therefore indicates some critical directions for further research. First, it would be valuable to analyze the effects of other word properties - word properties that relate specifically to the auditory aspects of words, such as phonotactic probabilities or spoken frequency and, for sign language, iconicity.

Second, we found ceiling effects in the two tasks that we used, even for the participants with hearing loss. These can most likely be attributed to the domain-specific criterion we adopted to select the target words. Despite these ceiling effects, however, we still found both task type and word type to differentially affect the children's vocabulary knowledge. Future research should use tasks and words that enable a better differentiation between children, for those with special educational needs, for the more able, and for those in the middle.

The children with normal hearing responded at least $90 \%$ correct to all clusters of words except for the specific words from Clusters 2 and 5 in the use decision task. It is generally assumed that one needs to know $90 \%$ of the words in a text in order to comprehend the text without problems (Hirsch, 2003). The children with normal hearing in our study can thus be assumed to "know" a sufficient number of words for adequate reading comprehension. However, the children with hearing loss only performed sufficiently on the common words in our two tasks and can therefore be expected to have considerable problems with reading comprehension.

During the last decades and largely due to the increasing number of children receiving cochlear implants (CIs; Geers, 2002; Svirsky, Teoh, \& Neuburger, 2004), the possibilities for children with severe to profound hearing loss to develop and use spoken language in particular have improved (Blamey, 2003). The results are variable (Marschark, Rhoten, \& Fabich, 2007); many children with a CI still comprehend fewer spoken words than their peers with normal hearing (Fagan, Pisoni, Horn, \& Dillon, 2007), and their vocabulary learning remains slower than that of their hearing peers (Nicholas \& Geers, 2007). The benefits of a CI for children with severe to profound hearing loss, particularly when done at an early age, are nevertheless clear (Blamey, 2003; Connor, Craig, Raudenbush, Heavner, \& Zwolan, 2006; Fagan \& Pisoni, 2010; Luckner \& Cooke, 2010). Other factors that have been found to influence (reading) vocabulary development of children with hearing loss following CI is a relatively later age of onset for the hearing loss (Powers, 2003), age of diagnosis (Moeller, 2000; Yoshinaga-Itano, 2003), degree of hearing loss (Kyle \& Harris, 2006), residual hearing prior to CI (El-Hakim et al., 2001), and communication mode (Connor, Hieber, Arts, \& Zwolan, 2000; El-Hakim et al., 2001; Geers, 2002; Hermans, et al., 2008; Spencer, 2004). Given our small sample size and the heterogeneity of such relevant background variables as age at implantation and duration of CI use (see the Appendix), we could not include these variables in our statistical analyses. In a previous study, however, we found that the heterogeneous composition of the participant group with hearing loss and the interrelatedness of such factors as degree of hearing loss, age at identification, type of hearing aids, and age of hearing aid initiation prevented us from demonstrating the effects of degree of hearing loss and CI use (Coppens, Tellings, van der Veld, Schreuder, \& Verhoeven, 2012). Additional research, possibly using different analytic techniques or a different research paradigm, is thus needed to tease apart the effect of these critical factors on reading vocabulary knowledge.

Finally, as a result of examining the clusters in the present study, we predict that different instruction strategies will work best for different word types. For example, the generic words of Cluster 3 (e.g., part and pressure) and of Cluster 4 (e.g., tall and long) derive their meaning nuance from the specific context they are in. Children probably need more practice to discern the different shades of meaning and may benefit from learning how to use context. For example, the word long can be used with dimensions: "a long train" or "a long hair"; to refer to a time interval: "a long story" or "a long time"; or even both: "a long way." Alternatively, the morphologically complex words of Clusters 1 and 2 (e.g., both compounds such as goldfish and bookcase, and derivationally complex words such as treasurer and childhood) probably benefit most from teaching a basic vocabulary and morphological principles. However, research is needed to examine whether the efficacy of different instruction methods depends on word type.

\section{Practical Implications}

The results of the present study have important implications for measuring and understanding the development of children's reading vocabulary. Measuring vocabulary is a complex matter because vocabulary knowledge constitutes a "large problem space" (Snow \& Kim, 2006).

Alphabetic languages such as Dutch and English draw upon a limited number of letters (i.e., 26) and phonemes for the formation of words, but the actual number of words encountered by children and other language learners is much, much larger. There is thus an enormous domain of words to choose from for assessment purposes, which raises the issue of which words to assess. Furthermore, there is the issue of what to assess. The model of Nation (1990) incorporates the multitude of vocabulary components, which range from letter to sentence to world knowledge and thus reflects the complexity of vocabulary knowledge. Our findings suggest that the size and complexity of the vocabulary problem space but also thereby the choice of words and tasks for assessment purposes can influence the conclusions that are drawn and sometimes lead to inappropriate conclusions or a distorted picture of either individual differences or group differences in vocabulary knowledge. The solution is to avoid oversimplification and try to take as many components of children's vocabulary knowledge into consideration as possible. Such broad assessment can further provide detailed insight into the differences in the reading vocabularies of children with and without hearing loss and where a particular child excels and lags behind - which types of words and tasks pose a problem for a child and which do not. 


\section{Acknowledgment}

This study was funded by the Netherlands Organization for Scientific Research Grant 400-05-119.

\section{References}

Auer, E. T., Bernstein, L. E., \& Tucker, P. E. (2000). Is subjective word familiarity a meter of ambient language? A natural experiment on effects of perceptual experience. Memory \& Cognition, 28, 789-797.

Baayen, R. H. (2005). Data mining at the intersection of psychology and linguistics. In A. Cutler (Ed.), Twenty-first century psycholinguistics: Four cornerstones (pp. 69-83). Mahwah, NJ: Erlbaum.

Baayen, R. H., Piepenbrock, R., \& Gulikers, L. (1995). The Celex lexical database (CD-ROM). Philadelphia: University of Pennsylvania, Linguistic Data Consortium.

Balota, D. A. (1994). Visual word recognition: The journey from features to meaning. In M. A. Gernsbacher (Ed.), Handbook of psycholinguistics (pp. 303-358). New York, NY: Academic Press.

Balota, D. A., \& Chumbley, J. I. (1984). Are lexical decisions a good measure of lexical access? The role of frequency in the neglected decision stage. Journal of Experimental Psychology, 10, 340-357.

Balota, D. A., Yap, M. J., \& Cortese, M. J. (2006). Visual word recognition: The journey from features to meaning (A travel update). In M. Traxler \& M. A. Gernsbacher (Eds.), Handbook of psycholinguistics (2nd ed., pp. 285-376). San Diego, CA: Elsevier.

Beck, I. L., \& McKeown, M. G. (1991). Conditions of vocabulary acquisition. In R. Barr, M. L. Kamil, P. Mosenthal, \& P. D. Pearson (Eds.), Handbook of reading research (2nd ed., Vol. 2, pp. 789-817). White Plains, NY: Longman.

Beck, S. W., \& Nabors Oláh, L. (Eds.). (2001). Perspectives on language and literacy: Beyond the here and now. Cambridge, MA: Harvard Education Press.

Blamey, P. J. (2003). Development of spoken language by deaf children. In M. Marschark \& P. E. Spencer (Eds.), Oxford handbook of deaf studies, language, and education (pp. 232-246). New York, NY: Oxford University Press.

Bloom, P., \& German, T. (2000). Two reasons to abandon the false belief task as a test of theory of mind. Cognition, 77, 25-31.

Connor, C. M., Craig, H. K., Raudenbush, S. W., Heavner, K., \& Zwolan, T. A. (2006). The age at which young deaf children receive cochlear implants and their vocabulary and speechproduction growth: Is there an added value for early implantation? Ear and Hearing, 27, 628-644.

Connor, C. M., Hieber, S., Arts, H. A., \& Zwolan, T. A. (2000). Speech, vocabulary, and the education of children using cochlear implants: Oral or total communication? Journal of Speech, Language, and Hearing Research, 43, 1185-1204.

Coppens, K. M., Tellings, A., van der Veld, W., Schreuder, R., \& Verhoeven, L. (2012). Vocabulary development in children with hearing loss: The role of child, family, and educational variables. Research in Developmental Disabilities, 33, 119-128.

Coppens, K. M., Tellings, A., Verhoeven, L., \& Schreuder, R. (2011). Depth of reading vocabulary in hearing and hearing-impaired children. Reading and Writing, 24, 463-477.

Cuetos, F., Monsalve, A., Pinto, A., \& Rodriguez-Ferreiro, J. (2004). Predictor variables of written picture naming in the deaf. Reading and Writing: An Interdisciplinary Journal, 17, 227-240.

Dale, E. (1965). Vocabulary measurement: Techniques and major findings. Elementary English, 42, 895-901, 948.

Dickinson, D. K., McCabe, A., \& Essex, M. J. (2006). A window of opportunity we must open to all: The case for preschool with high quality support for language and literacy. In D. Dickinson \& S. Neuman (Eds.), Handbook of early literacy research (2nd ed., pp. 11-28). New York, NY: Guilford.

Dunn, L. M., \& Dunn, D. M. (1997). Peabody Picture Vocabulary Test-III. Circle Pines, MN: AGS.

El-Hakim, H., Levasseur, J., Papsin, B. C., Panesar, J., Mount, R. J., Stevens, D., \& Harrison, R. V. (2001). Assessment of vocabulary development in children after cochlear implantation. Archives of Otolaryngology-Head \& Neck Surgery, 127, 1053-1060.

Fagan, M. K., \& Pisoni, D. B. (2010). Hearing experience and receptive vocabulary development in deaf children with cochlear implants. Journal of Deaf Studies and Deaf Education, 15, 149-161.

Fagan, M. K., Pisoni, D. B., Horn, D. L., \& Dillon, C. M. (2007). Neuropsychological correlates of vocabulary, reading, and working memory in deaf children with cochlear implants. Journal of Deaf Studies and Deaf Education, 12, 461-471.

Fischler, I. (1985). Word recognition, use of context, and reading skill among deaf college students. Reading Research Quarterly, 20, 203-218.

Geers, A. E. (2002). Factors affecting the development of speech, language, and literacy in children with early cochlear implantation. Language, Speech, and Hearing Services in Schools, 33, 172-183.

Hanson, V. L., Shankweiler, D., \& Fischer, F. W. (1983). Determinants of spelling ability in deaf and hearing adults: Access to linguistic structure. Cognition, 14, 323-344.

Hart, B. (1991). Input frequency and children's first words. First Language, 11, 289-300.

Hermans, D., Knoors, H., Ormel, E., \& Verhoeven, L. (2008). Modeling reading vocabulary learning in deaf children in bilingual education programs. Journal of Deaf Studies and Deaf Education, 13, 155-174.

Hirsch, E. D., Jr. (2003). Reading comprehension requires knowledge - of words and the world: Scientific insights into the fourth-grade slump and the nation's stagnant comprehension scores. American Educator, 27, 10-13, 16-22, 28-29, 44- 45.

Huibregtse, I., Admiraal, W., \& Meara, P. (2002). Scores on a yes-no vocabulary test: Correction for guessing and response style. Language Testing, 19, 227-245.

Huttenlocher, J., Haight, W., Bryk, A., Seltzer, M., \& Lyons, T. (1991). Early vocabulary growth: Relation to language input and gender. Developmental Psychology, 27, 236-248.

Kelly, L. (1996). The interaction of syntactic competence and vocabulary during reading by deaf students. Journal of Deaf Studies and Deaf Education, 1, 75-90.

Kyle, F. E., \& Harris, M. (2006). Concurrent correlates and predictors of reading and spelling achievement in deaf and hearing school children. Journal of Deaf Studies and Deaf Education, 11, 273-288.

LaSasso, C., \& Davey, B. (1987). The relationship between lexical knowledge and reading comprehension for prelingually, profoundly hearing-impaired students. The Volta Review, 89 , 211-220.

Lederberg, A. R., Preszbindowski, A. K., \& Spencer, P. E. (2000). Word-learning skills of deaf preschoolers: The development of novel mapping and rapid word learning strategies. Child Development, 71, 1571-1585.

Leybaert, J. (1993). Reading in the deaf: The roles of phonological codes. In M. Marschark \& M. D. Clark (Eds.), Psychological perspectives on deafness (Vol. 1, pp. 269-308). Hillsdale, NJ: Erlbaum.

Luckner, J. L., \& Cooke, C. (2010). A summary of the vocabulary research with students who are deaf or hard of hearing. American Annals of the Deaf, 155, 38-67. 
Ludwig, J. (1984). Vocabulary acquisition as a function of word characteristics. Canadian Modern Language Review, 40, 552-562.

Luetke-Stahlman, B., \& Nielsen, D. C. (2003). The contribution of phonological awareness and receptive and expressive English to the reading ability of deaf students with varying degrees of exposure to accurate English. Journal of Deaf Studies and Deaf Education, 8, 464484.

Magnini, B., Strapparava, C., Pezzulo, G., \& Gliozzo, A. (2002). The role of domain information in word sense disambiguation. Natural Language Engineering, 8, 359-373.

Marcolini, S., Burani, C., \& Colombo, L. (2009). Lexical effects on children's pseudoword reading in a transparent orthography. Reading and Writing, 22, 531-544.

Marschark, M., Convertino, C., McEvoy, C., \& Masteller, A. (2004). Organization and use of the mental lexicon by deaf and hearing individuals. American Annals of the Deaf, 149, 51-61.

Marschark, M., Lang, H. G., \& Albertini, J. A. (2002). Educating deaf students: From research to practice. New York, NY: Oxford University Press.

Marschark, M., Rhoten, C., \& Fabich, M. (2007). Effects of cochlear implants on children's reading and academic achievement. Journal of Deaf Studies and Deaf Education, 12, 269-282.

Mayberry, R. I. (2002). Cognitive development of deaf children: The interface of language and perception in neuropsychology. In S. J. Segalowitz, \& I. Rapin (Eds.), Handbook of neuropsychology, Part II (2nd ed., Vol. 8, pp. 71-107). Amsterdam, the Netherlands: Elsevier.

Mayer, C. (2007). What really matters in the early literacy development of deaf children. Journal of Deaf Studies and Deaf Education, 12, 411-413.

McEvoy, C., Marschark, M., \& Nelson, D. L. (1999). Comparing the mental lexicon of deaf and hearing individuals. Journal of Educational Psychology, 91, 312-320.

McKeown, M. G., Beck, I. L., Omanson, R. C., \& Pople, M. T. (1985). Some effects of the nature and frequency of vocabulary instruction on the knowledge and use of words. Reading Research Quarterly, 20, 522-535.

Miller, G. A. (1999). On knowing a word. Annual Review of Psychology, 50, 1-19.

Moeller, M. P. (2000). Early intervention and language development in children who are deaf and hard of hearing. Pediatrics, 106, e43. doi:10.1542/peds.106.3.e43

Nation, I. S. P. (1990). Teaching and learning vocabulary. Boston, MA: Heinle and Heinle.

Nicholas, J. G., \& Geers, A. E. (2007). Will they catch up? The role of age at cochlear implantation in the spoken language development of children with severe to profound hearing loss. Journal of Speech, Language, and Hearing Research, 50, 1048-1062.

Ormel, E. (2008). Visual word recognition in bilingual deaf children (Unpublished doctoral dissertation). Radboud University Nijmegen, the Netherlands.

Paul, P. V. (1996). Reading vocabulary knowledge and deafness. Journal of Deaf Studies and Deaf Education, 1, 3-15.

Paul, P. V. (2001). Language and deafness (3rd ed.). San Diego, CA: Singular/Thomson-Learning.

Paul, P. V. (2003). Processes and components of reading. In M. Marschark \& P. E. Spencer (Eds.), Oxford handbook of deaf studies, language and education (pp. 97-109). New York, NY: Oxford University Press.

Paul, P. V., \& Gustafson, G. (1991). Comprehension of highfrequency multimeaning words by students with hearing impairment. Remedial and Special Education, 12(4), 52-62.
Paul, P. V., \& Lee, C. (2010). The qualitative similarity hypothesis. American Annals of the Deaf, 154, 456-462.

Powers, S. (2003). Influences of student and family factors on academic outcomes of mainstream and secondary school deaf students. Journal of Deaf Studies and Deaf Education, 8, 57-78.

Read, J. (2000). Assessing vocabulary. Cambridge, United Kingdom: Cambridge University Press.

Reutzel, D. R., \& Cooter, R. B., Jr. (2004). Teaching children to read: Putting the pieces together (4th ed.). Upper Saddle River, NJ: Pearson.

Schreuder, R., \& Baayen, R. H. (1997). How complex simplex words can be. Journal of Memory and Language, 37, 118-139.

Snow, C. E., \& Kim, Y.-S. (2006). Large problem spaces: The challenge of vocabulary for English language learners. In R. K. Wagner, A. Muse, \& K. Tannenbaum (Eds.), Vocabulary acquisition and its implications for reading comprehension (pp. 123-139). New York, NY: Guilford.

Spencer, P. E. (2004). Individual differences in language performance after cochlear implantation at one to three years of age: Child, family, and linguistic factors. Journal of Deaf Studies and Deaf Education, 9, 395-412.

Spencer, P. E., \& Lederberg, A. R. (1997). Different modes, different models: Communication and language of young deaf children and their mothers. In L. B. Adamson \& M. A. Romski (Eds.), Communication and language acquisition: Discoveries from atypical development (pp. 203-230). Baltimore, MD: Brookes.

Svirsky, M. A., Teoh, S. W., \& Neuburger, H. (2004). Development of language and speech perception in congenitally, profoundly deaf children as a function of age at cochlear implantation. Audiology and Neurotology, 9, 224-233.

Tellings, A., Coppens, K., Gelissen, J., \& Schreuder, R. (2013). Clusters of word properties as predictors of elementary school children's performance on two word tasks. Applied Psycholinguistics, 34, 461-481.

van Bon, W. H. J. (2007). Doorstreepleestoets [Pencil-and-paper lexical-decision task]. Leiden, the Netherlands: PITS B.V.

van Boxtel, H. W., \& Hemker, B. T. (2009). Wetenschappelijke Verantwoording van de Intelligentietest Eindtoets Basisonderwijs [Scientific account for the Intelligence test End of Elementary School Test]. Arnhem, the Netherlands: Cito.

Vermunt, J. K., \& Magidson, J. (2000). Latent GOLD's user's guide. Boston, MA: Statistical Innovations.

Wauters, L. N., Tellings, A. E. J. M., van Bon, W. H. J., \& Mak, W. M. (2008). Mode of acquisition as a factor in deaf children's reading comprehension. Journal of Deaf Studies and Deaf Education, 13, 175-192.

Wauters, L. N., van Bon, W. H. J., \& Tellings, A. E. J. M. (2006). Reading comprehension of Dutch deaf children. Reading and Writing, 19, 49-76.

Wauters, L. N., van Bon, W. H. J., Tellings, A. E. J. M., \& van Leeuwe, J. F. J. (2006). In search of factors in deaf and hearing children's reading comprehension. American Annals of the Deaf, 151, 371-380.

Weizman, Z. O., \& Snow, C. E. (2001). Lexical input as related to children's vocabulary acquisition: Effects of sophisticated exposure and support for meaning. Developmental Psychology, 37, 265-279.

Woodcock, R. W. (1987). Woodcock Reading Mastery TestsRevised. Circle Pines, MN: AGS.

Yoshinaga-Itano, C. (2003). From screening to early identification and intervention: Discovering predictors to successful outcomes for children with significant hearing loss. Journal of Deaf Studies and Deaf Education, 8, 11-30. 


\section{Appendix}

Background Information on the 72 Children With Hearing Loss

\begin{tabular}{lr} 
Language used at home & \\
Spoken Dutch & 26 \\
Sign Language of the Netherlands & 1 \\
Sign-supported Dutch & 6 \\
Other spoken language & 4 \\
Spoken Dutch and Sign Language of the Netherlands & 3 \\
Spoken Dutch combined with sign-supported Dutch & 20 \\
Other spoken language combined with sign-supported & 4 \\
Dutch & \\
Sign Language of the Netherlands and sign-supported & 5 \\
Dutch & \\
Other combinations & 4 \\
Onset hearing loss & \\
Born with hearing loss & 52 \\
Hearing loss before age 3 years & 18 \\
Hearing loss after age 3 years & 2 \\
Hearing loss better unaided ear & 26 \\
80-100 dB & 25 \\
100-120 dB & 21 \\
Z120 dB & 6 \\
Hearing Devices & 19 \\
No device & 16 \\
Conventional hearing aid & 27 \\
Cl after age 5 years & 4 \\
Cl between age 2 and 5 years & \\
Cl before age 2 years & 26 \\
Educational placement & \\
Mainstream education & 46 \\
Special school & 18 \\
Family members & 54 \\
Family members with hearing loss \\
No family members with hearing loss & \\
\hline
\end{tabular}

Note. Children in mainstream education were educated in Dutch; children in special schools were educated bilingually using spoken Dutch and Sign Language of the Netherlands. 